\title{
Heterogeneity of the remaining lifespan of table grapes in refrigerated transportation
}

\author{
Cíntia Carla Melgaço de OLIVEIRA ${ }^{1,2 *}$ (D), Davi Rocha Bernardes de OLIVEIRA ${ }^{1}$, Wigberto Antonio SPAGNOL ${ }^{1}$, \\ Lucas Ramos TAVARES ${ }^{3}$, Vivaldo SILVEIRA JUNIOR ${ }^{1}$
}

\begin{abstract}
This work aimed to show heterogeneities in shelf life of table grapes from a same batch during road refrigerated transportation. The monitoring of temperature and relative humidity of air was done with a wireless sensor network strategically distributed among grapes boxes and pallets. The ambient conditions and time of exposure were associated with a linear predictive model of water loss in order to estimate fruits shelf life. Results showed that the loss of dynamic life of grapes varied according to the box position on different pallets within the refrigerated transport vehicle, due to differences in the conditions that fruits were exposed to. It was observed high heterogeneity in shelf life of the evaluated batch of grapes during transportation, with differences of 71 days between grape boxes. With that, one can conclude that these differences must be taken into account in the following stages of grapes cold chain.
\end{abstract}

Keywords: refrigerated transport; ambient condition; wireless sensors network; predictive model; water loss; shelf life.

Practical Application: Heterogeneity in air conditions within grape transport vehicles directly affect their lifespan.

\section{Introduction}

Transport is one of the stages of production and distribution chains with significant losses and damages to perishable products (Derens-Bertheau et al., 2015; Jedermann et al., 2011; RuizGarcia \& Lunadei, 2010). It happens mainly because the food remains for long periods exposed to high variable ambient conditions, due to the thermal amplitude. Due to its location and the high territorial extension, Brazil has different types of climate, which makes the accommodation of perishable products in adequate climate conditions a fundamental step. It serves both to maintain the quality of the product until the next stage in the distribution chain and to be accessible to different locations. Unfortunately, not all productive chains transport their perishable products under appropriate environmental conditions. It might happen due to the lack of infrastructure and knowledge of how environmental conditions affect product quality.

During transportation and storage, fresh grapes are subjected to deterioration, caused mainly by grapes aerobic and exothermic metabolism, generating $\mathrm{CO}_{2}$ and water, the sugar content (15 to $17^{\circ} \mathrm{Brix}$ ) and microorganisms' growth. This deterioration affects the product losses, which can vary from 30 to $50 \%$, depending on the exposure time to the local ambient conditions. The temperature and relative humidity conditions used for conservation influence directly grapes deterioration and product losses (Sonker et al., 2016). Despite being non-climacteric fruits, showing low physiological activity, table grapes are very sensitive to dehydration during post-harvest operations and in the different stages of the logistics chain (Artés-Hernández et al., 2006). In addition to dehydration, degranulation and rotting are other issues that affect grapes quality, which can be controlled by the appropriate use of post-harvest and cold chain technologies (Crisosto et al., 2001; Lopresti et al., 2016).

The process of water loss in grape clusters occurs through transpiration. It includes the transport of water through the anatomical structures of living tissues (lenticels, stomata, cuticles, peduncles and regions of the peduncle insertion into the fruit) to the surface, evaporation and the mass transfer of this water by convection to the ambient air (Becher et al., 1995; Cantwell, 2015). These intrinsic factors are quantified by the mass transfer rate depending on the global mass transfer coefficient (Pereira et al., 2017). It is possible to reduce this mass transfer process by lowering the air temperature and increasing its relative humidity. In this way, the speed of metabolic reactions and the difference in water vapor pressure between the external surface of the fruit and the ambient air can be reduced (Kader, 2002; RuizGarcia et al., 2008). Some authors recommend a storage temperature between -1 and $0{ }^{\circ} \mathrm{C}$ for ripe grapes (Crisosto et al., 2001) and $2{ }^{\circ} \mathrm{C}$ for refrigerated transportation temperature of fresh grapes (Thompson, 2002). In addition, the relative humidity (RH) recommended for fresh grapes conservation ranges between 90 and 95\% (Crisosto et al., 2001), with an air volumetric rate ranging from 0.57 to $1.13 \mathrm{~m}^{3} \mathrm{~min}^{-1}$ during storage.

Small deviations in ideal storage conditions significantly increase the quality loss rate of table grapes, decreasing its shelf life (Lopresti et al., 2016). Perishable products shelf life can be defined as a dynamic value related to the remaining expected acceptable product quality, dependent on the storage and transportation ambient conditions in each stage of logistic chain. The ambient condition

${ }^{1}$ Departamento de Engenharia de Alimentos, Faculdade de Engenharia de Alimentos, Universidade Estadual de Campinas - UNICAMP, Campinas, SP, Brasil

${ }^{2}$ Laboratório de Automação e Controle de Processos em Alimentos - LACPA, Departamento de Engenharia de Alimentos - DEA, Faculdade de Engenharia de Alimentos -

FEA, Universidade Estadual de Campinas - UNICAMP, Campinas, SP, Brasil

${ }^{3}$ Instituto de Matemática, Estatística e Computação Científica, Universidade Estadual de Campinas - UNICAMP, Campinas, SP, Brasil

*Corresponding author: cintiamelgaco@hotmail.com 
historic, starting at the product harvesting, can conditionally define its actual remaining life (Aung \& Chang, 2014).

For most foods, shelf life can be represented by some property change as a function of time. It is important to mention that the quality loss is always cumulative, i.e., each physical incident caused by incorrect food manipulation reduce its quality before it reaches the final destination (consumers) (Sargent et al., 2007). Because all of that, the determination of perishable products shelf life is a fundamental step that can influence all post harvesting logistics. One way to determine the actual shelf life of table grapes or other perishable foods are the utilization of an algorithm that can estimate changes in a generic property of a specific perishable product, such as its water content. This can be made, indirectly, by determining the loss of mass or water from the food, and correlating it with the ambient air conditions (temperature and humidity) and the corresponding exposure time.

In order to correlate the water loss of perishable foods with the ambient conditions, the latter must be very well monitored. Even with the technology available, its known that its application is not usual in most of global supply networks. It is well known that the key drawback that contributes to the elevated losses of perishable food is the inability to monitor and control the temperature and relative humidity of the environments where the food is exposed or stored (Badia-Melis et al., 2018). In refrigerated transportation, a single sensor installed near the door usually monitors the ambient air conditions within the vehicle, and, in general, measures only the temperature. This monitoring condition has been proved to be insufficient, as it does not consider the actual distribution of air conditions inside the refrigerated truck body. Some studies exposed a temperature fluctuation of several degrees above and below the specified set point inside the transport chambers, cooling chambers and cold storage rooms (Ruiz-Garcia et al., 2008). In addition, it has been stated that the number of sensors for monitoring is insufficient, using a maximum of two temperature sensors and almost never relative humidity ones. Moreover, the commercial refrigeration system with an on-off type temperature control is inadequate, since it results in undesirable oscillations (Jedermann et al., 2009; Ruiz-Garcia et al., 2010a, b).

Thus, due to the heterogeneous ambient conditions that perishable products are exposed, especially during refrigerated transportation, assuming them with the same shelf life, usually defined in their origin, can cause deficiencies in the logistical distribution management, generating higher food losses. Thus, the objective of this work was to show the effect of ambient actual ambient air conditions, including temperature and relative humidity, in which table grapes were exposed during their refrigerated transportation from the factory to the distribution center, relating it to the fruits actual predicted shelf life.

\section{Materials and methods}

\subsection{Ambiental conditions monitoring within refrigerated transport}

The transport conditions within the refrigerated truck (time, temperature and relative humidity) were monitored on a $2400 \mathrm{~km}$ route of Sweet Jubilee grapes in this case study, with specific consequences for this assay, with possible similarities to other case reports. In this way, replicates of the transport assays were not possible to be performed. In no time was there any interferences in the management routine performed by the evaluated company, in order to have a realistic history of the entire logistics process and its impact on the fruits shelf life.

$500 \mathrm{~g}$ of grape bunches were selected and packed in plastic bowls, wrapped in a perforated plastic film, impregnated with metabisulfite, and placed inside cardboard boxes. These boxes were stacked forming pallets with 22 layers of boxes, 5 boxes in each layer and 10 bowls in each box, totaling approximately $550 \mathrm{~kg}$ of table grapes in each pallet. The pallets boxes columns were identified by the letters A to E, and the box layers by numbers from 1 to 22, as shown in Figure 1a.

The refrigerated truck body, with internal dimensions of $2.4 \times 14.0 \times 3.0 \mathrm{~m}$, was loaded with 28 grape pallets distributed in two rows. The temperature of the chamber was adjusted to $4{ }^{\circ} \mathrm{C}$. The monitored pallets were positioned with columns A, B and $\mathrm{C}$ facing the chamber door. In order to monitor the regions of higher and lower temperature, the small openings of boxes in columns D and E, in which the sensors were installed, were directed to the side and to the center regions of the chamber, respectively. Fourteen of the 28 pallets were monitored (P01, P04, P05, P08, P09, P12, P13, P16, P17, P20, P21, P24, P25 and $\mathrm{P} 28)$ with temperature and relative humidity sensors located at the bottom (D02) and upper (E20) pallet parts, as shown in Figure $1 \mathrm{~b}$. In this way, the pallets located at the left side had the sensors installed in the D02 boxes, positioned at the bottom and close to the sidewall. Meanwhile, the sensors installed in the E20 boxes were located close to the top and the center of the refrigerated chamber. On the other hand, for the pallets located at the right side of the truck body, the sensors in boxes D02 were positioned in the bottom and central part of the chamber, while the sensors in boxes E20 were positioned in the upper part and close to the sidewall. In addition to the aforementioned sensors, two sensors were also installed near the door, one on pallet 27 in position B02 and another one on pallet 28 in position C22, together with the company's only monitoring sensor. In total, 30 sensors were strategically distributed inside the refrigerated transport vehicle.

The monitoring of product conservation conditions during refrigerated transport was performed using the Xsense ${ }^{\varpi}$ technology (BT9, London, UK). Time, temperature and relative humidity data were collected at hourly intervals until synchronization with the antenna available at the distribution center, where they transmitted to a centralized database.

\subsection{Calculation of mass loss and shelf life of table grapes}

In order to assess the impact of ambient air conditions that table grapes were exposed to during transportation, we sought to estimate the loss of water mass and grapes shelf life before they get considered as rejected by final consumers. To calculate the loss of water, a linear mass transfer model was used, as presented by Equation 1 (Sastry \& Buffington, 1983). It is based on the solution for the steady state of Fick's first law, where there is a linear relationship between the respective variables. In this 
(a)

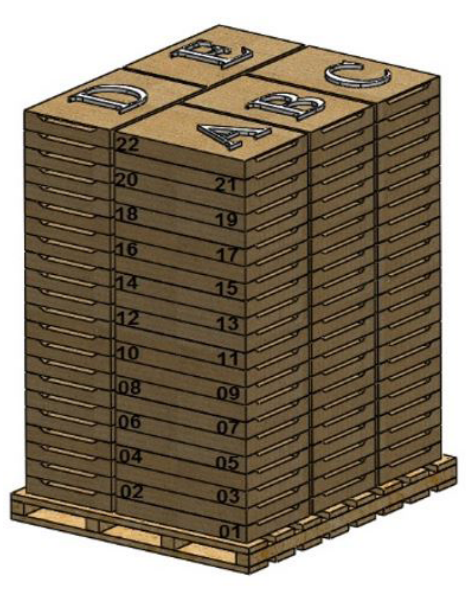

(b)
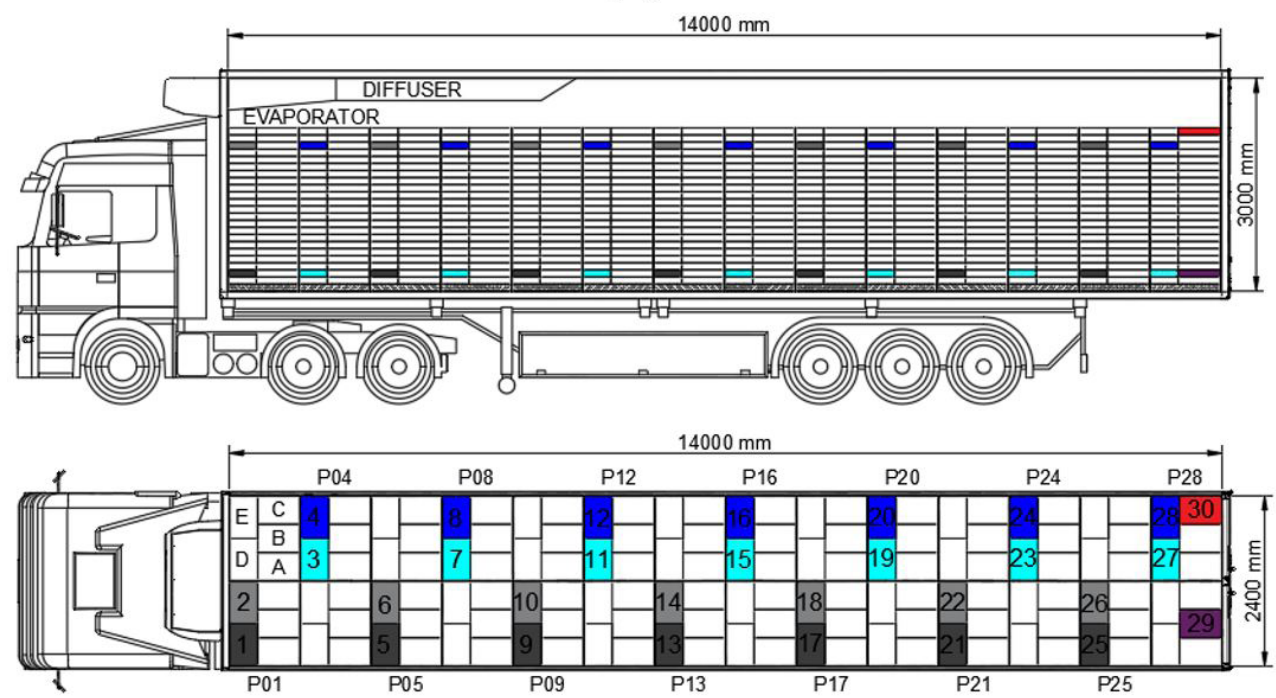

Figure 1. (a) The positioning of the boxes on each pallet; (b) Location of sensors installed in the boxes/pallets during the refrigerated transport monitoring.

model, the maximum availability of water vapor on the grape surface was considered constant, i.e., saturation pressure at the surface temperature.

$$
T T=k_{t}\left(P_{s}-P_{v}\right)
$$

where $T T$ is the water loss rate by product weight unit $\left(\mathrm{g} \mathrm{kg}^{-1} \mathrm{~h}^{-1}\right) ; P_{s}$ is the water saturation pressure on grapes surface $(\mathrm{Pa}) ; P_{v}$ is the ambient vapor pressure $(\mathrm{Pa})$; and $k_{t}$ is the transpiration coefficient and equal to $0.000443\left(\mathrm{~g} \mathrm{~kg}^{-1} \mathrm{~h}^{-1} \mathrm{~Pa}^{-1}\right)$ for grapes (Sastry et al., 1978). This value was used due to the lack of a specific coefficient for the Sweet Jubilee grape variety packaged in plastic bowls and cardboard boxes.

The water vapor pressure at the evaporation surface was considered as the water saturation pressure, since it was a freshly harvested product, at the temperature of the fruit close to the monitored air. It was estimated using the Antoine equation (Antoine, 1888) (Equation 2), while the ambient water vapor pressure was estimated using Equation 3.

$\ln \left[P_{s}(T) \cdot 133,32^{-1}\right]=A-\left[B \cdot(T+C)^{-1}\right]$

$P_{v}=P_{s} \cdot(R H) \cdot 100^{-1}$

where A, B and C are Antoine equation coefficients. For water, their values are $18.30,3816.44$ and -46.13 , respectively; $\mathrm{T}$ is the air temperature, which was considered equal to the grape surface temperature (K); and RH is the air relative humidity (\%).

The dynamic and cumulative mass loss of grape bunches by transpiration was determined using Equation 4 (Leonardi et al., 1999). This equation considers the mass loss rate as a zero order kinetics $\left(\mathrm{n}=0\right.$, for $\left.\frac{d M}{d t}=T^{\grave{y}} \cdot M^{n}\right)$. The prediction is for the kinetics of constant mass loss up to $10 \%$, considering the fruit surface is always saturated.

$$
M_{f}=M_{o}-\sum_{j}\left(\dot{T} T \cdot M_{0} \cdot t \cdot 1000^{-1}\right)
$$

where $M_{f}$ is the final grape mass (g); $M_{o}$ is the initial grape mass $(\mathrm{g}) ; t$ is time $(\mathrm{h}) ; j$ is the index of the summation in which $T T$ is in changed environmental conditions and times.

The fruits shelf life, that is, its remaining life before rejection by the consumer, was also determined. For this, a maximum water loss of 5\% in relation to the initial mass of the fruit was considered as the acceptable quality limit for grapes, considering that they will be maintained under the best storage situation $\left(0^{\circ} \mathrm{C}\right.$ and $95 \%$ of $\mathrm{RH}$ ) at the next stages of the cold chain. Thus, we calculated the time remaining for the grape to lose $5 \%$ of its initial mass, considering the water loss occurring cumulatively until the end of the transportation stage (Equation 5).

$t_{\text {rem }}=\frac{\left(M_{\left(0,05 M_{o}\right)}-M_{\text {prev stage }}\right) 1000}{\dot{T} T_{\left(0^{\circ} C ; 95 \% R H\right)^{M}}^{M_{o}}}$

where $t_{\text {rem }}$ is the fruit shelf life before its rejection (h); $\mathrm{M}_{\left(0,05 \mathrm{M}_{0}\right)}$ is the grape mass after lose $5 \%$ of its initial mass $\left(M_{0}\right)(\mathrm{g}) ; M_{\text {prev stage }}$ is the grape mass at the end of transportation stage $(\mathrm{g}) ; T^{T} T_{\left(0^{\circ} \mathrm{C} ; 95 \% \mathrm{RH}\right)}$ is the grape mass loss rate per mass unit $\left(\mathrm{g} \mathrm{kg}^{-1} \mathrm{~h}^{-1}\right)$ at the best storage condition.

\section{Results and discussion}

\subsection{Behavior of ambient conditions within the refrigerated vehicle}

It was observed high variations in temperature and relative humidity along the length of the transport cold chamber. This occurred mainly due to the air distribution inside the chamber and external interferences, such as sunlight incidence. Figure 2 shows the historic of temperature and 


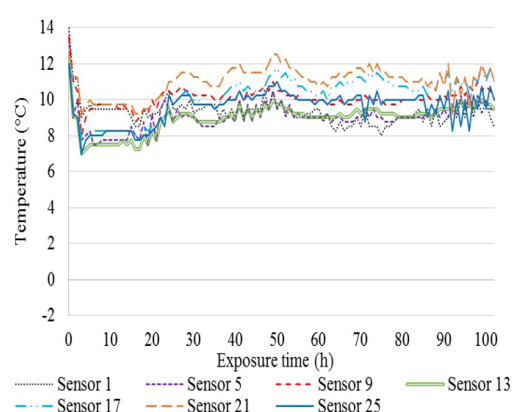

(a)

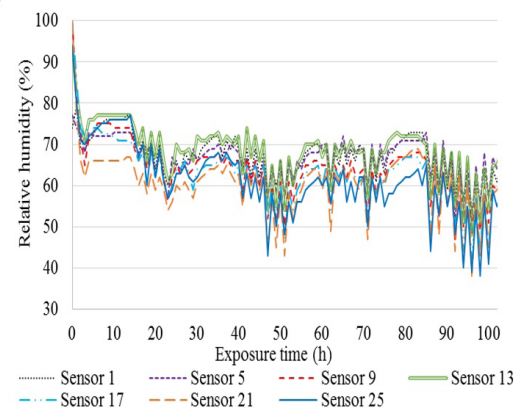

(b)
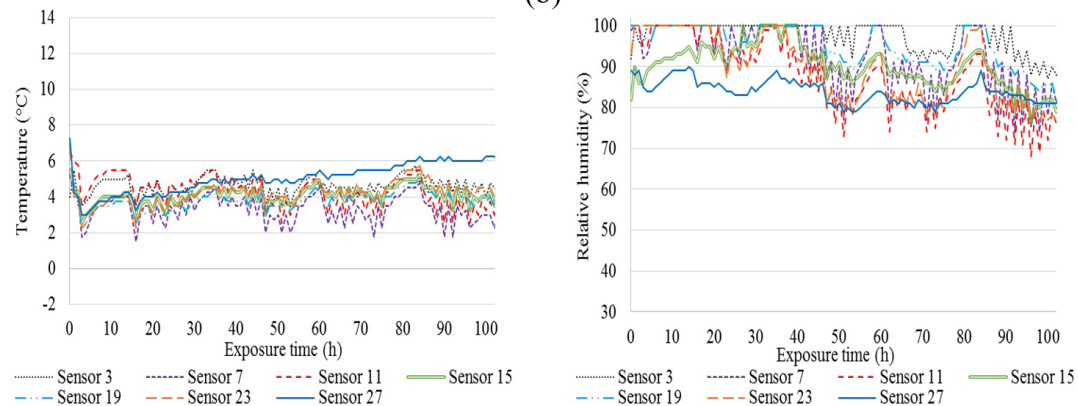

(c)
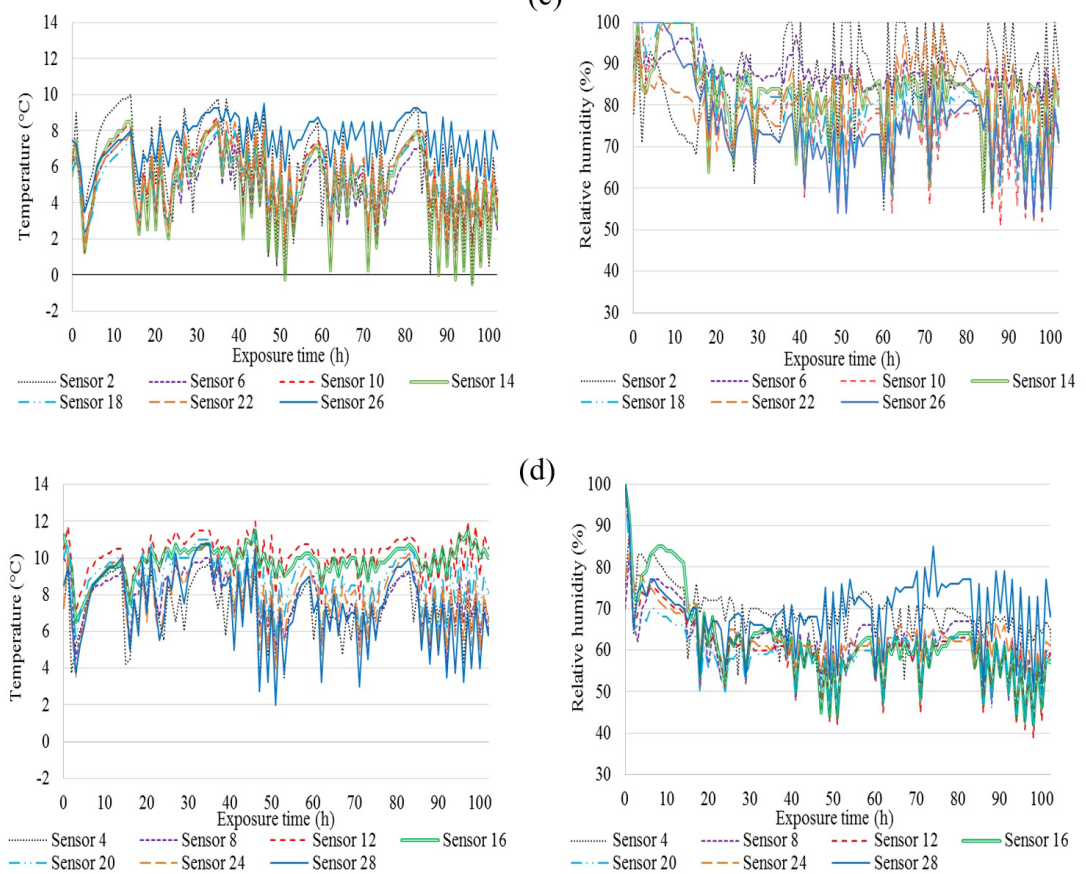

(d)
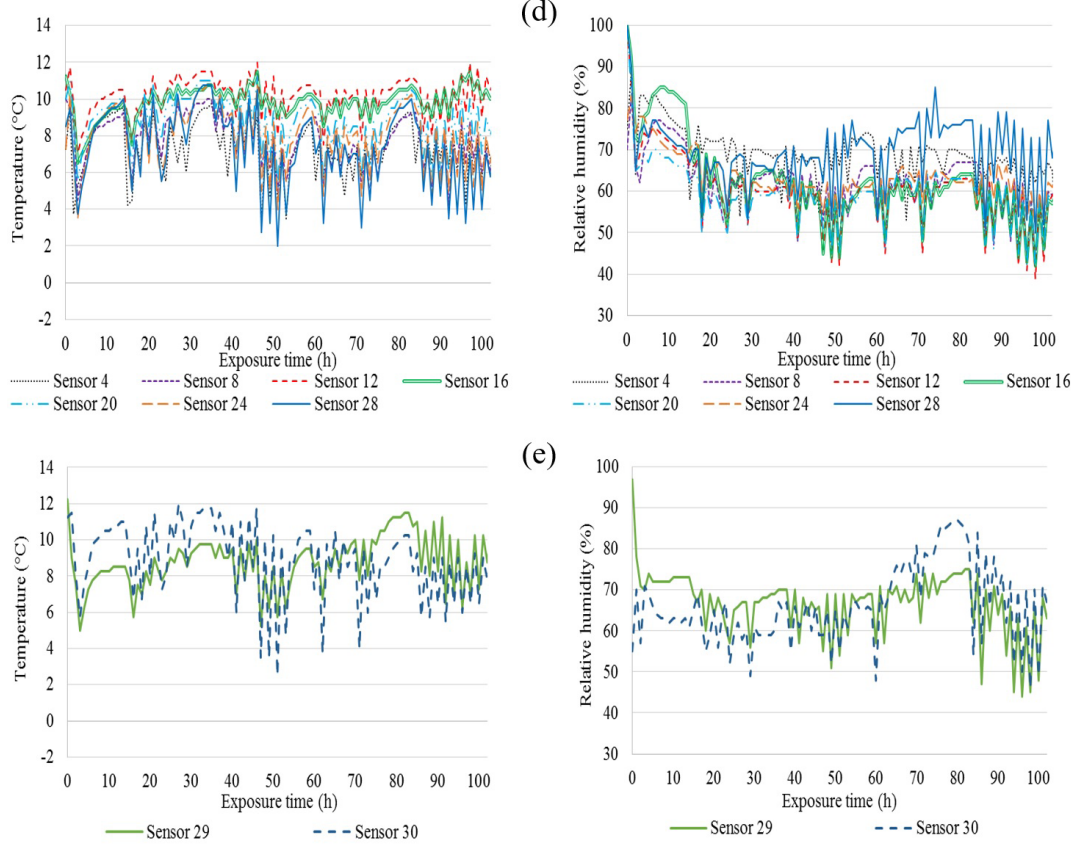

(e)

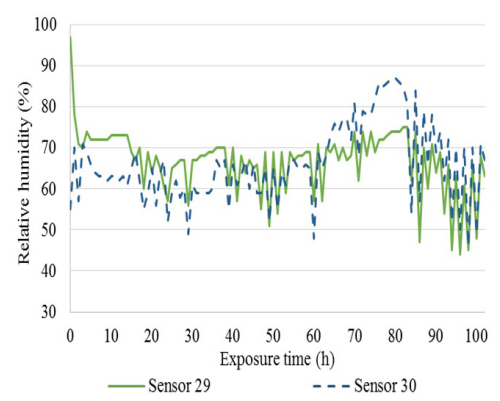

Figure 2. Historic temperature and relative humidity data for the air inside the refrigerated transport registered by the sensors installed in each evaluated position in the monitored pallets during grape transport stage. (a) Lower left side sensors (D02); (b) lower center sensors (D02); (c) upper center sensors (E20); (d) upper right side sensors (D20); and (e) door parallel sensors (B02 and C22). 
relative humidity of the air inside the refrigerated transport collected by sensors installed in the monitored pallets. Temperature collected data ranged from -0.5 to $14^{\circ} \mathrm{C}$, while the relative humidity varied between 38 and 100 . The chamber sides reached the highest temperatures, mainly in lower positions, close to the chamber floor. In the central positions of the refrigerated transport, the lowest temperatures were observed. The temperature magnitudes in the center lower region were similar to the set point defined in refrigeration system control. It happened mainly due to the higher density of cooled air and the evaporator positioning, located right in the center of the chamber ceiling. Another studies have also shown similar behavior inside a refrigerated vehicle, where high temperature fluctuations were observed and the center region showed lower temperatures when compared to the side regions (Ruiz-Garcia et al., 2010a, b).

In addition to the temperatures being higher than the adequate values for fruits transportation in most of the chamber interior, oscillations in their values can cause expressive water vapor condensation on grapes surface, allowing the proliferation of microorganisms. Regarding relative humidity within the transport vehicle, the lower center region showed the highest values, ranging between 80 and $100 \%$ in most of the monitored time. The upper central region showed high oscillations in RH values. The refrigerated chamber sides showed relative humidity values below $70 \%$ over most of the chamber length, reaching magnitudes below $40 \%$. These low $\mathrm{RH}$ values do not favor the fruits preservation and may result in high water loss for grapes located in these regions, due to the greater differential of water vapor pressures between the fruit and the ambient air. This water loss result in a lower mass of the product that will be marketed, and, mainly, influences in the fruit final quality, resulting in products with lower added values due to its appearance depreciation, or even the leading to rejection by the consumers. The air relative humidity is a parameter that usually is not considered in the control of refrigerated transport.

Based on the aforementioned behaviors of the ambient conditions that table grapes were exposed to during the refrigerated transportation, it was possible to observe the poor distribution of air inside the refrigerated vehicle and its insulation deficiency. It was also noted the incorrect positioning of the temperature sensor used to control the refrigeration system. It measures the temperature of the returned air to the evaporator. The way it was installed, it was probably measuring the air returning from the lower central region, which presented the lower temperatures, not considering the other chamber regions where the temperatures were considerably higher. This fact could be observed by analyzing the temperature of the refrigerated chamber lower central region (Figure $2 b$ ), which showed little variation and values close to $4{ }^{\circ} \mathrm{C}$, which was the defined set-point of the refrigeration system. Base on that, one can say that the infrastructure and the way of operation in refrigerated transport directly influence the products quality and consequently their shelf lives.

In order to assess the air distribution and along the refrigerated vehicle internal extension during the transportation period
(102 hours), the mean temperatures and relative humidity at each monitored point were calculated, as shown in Figure 3. The first 3 hours of transport were disregarded to allow the temperature stabilization after the fruit cargo load.

Observing the behavior of the air distribution inside the refrigerated transport, one can clearly see the heterogeneity of air temperature and relative humidity in its all extension. The mean values for temperature and relative humidity of between for sensors located in similar positions in the five evaluated regions of the refrigerated chamber (positions D02 (lower left side), D02 (lower center), E20 (upper center), E20 (upper right side) and B02 and C22 (parallel to door)) are shown in Table 1.

The positions D02 (lower left side), E20 (upper right side), and B02 and C22 (parallel to door) were statistically similar, both for temperature and relative humidity. These regions differed from the ambient conditions in the central positions (D02 (lower) and E20 (upper)), which were different statistically from each other at $5 \%$ of significance.

In order to evaluate the heterogeneity of ambient conditions on a pallet, the significant differences between data collected by sensors installed on a same pallet are shown in Table 2.

It can be seen that in most of the monitored pallets there was heterogeneity of the ambient conditions, regarding both

(a)

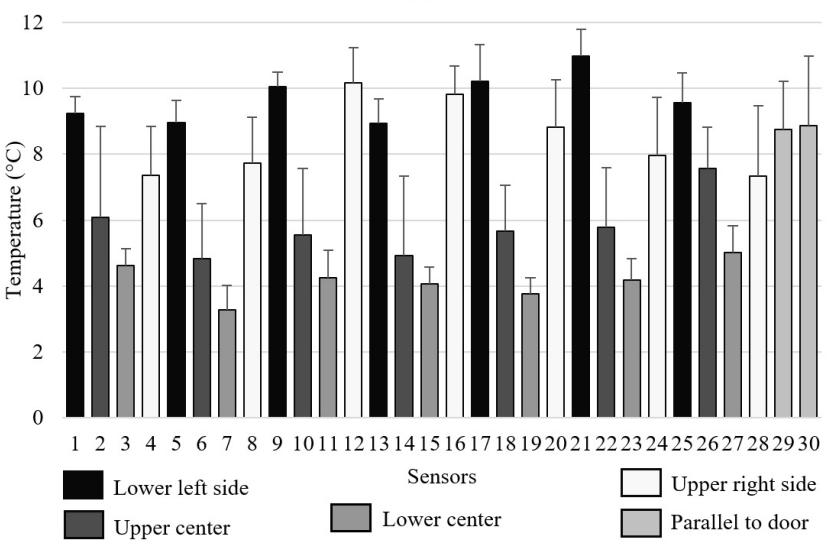

(b)

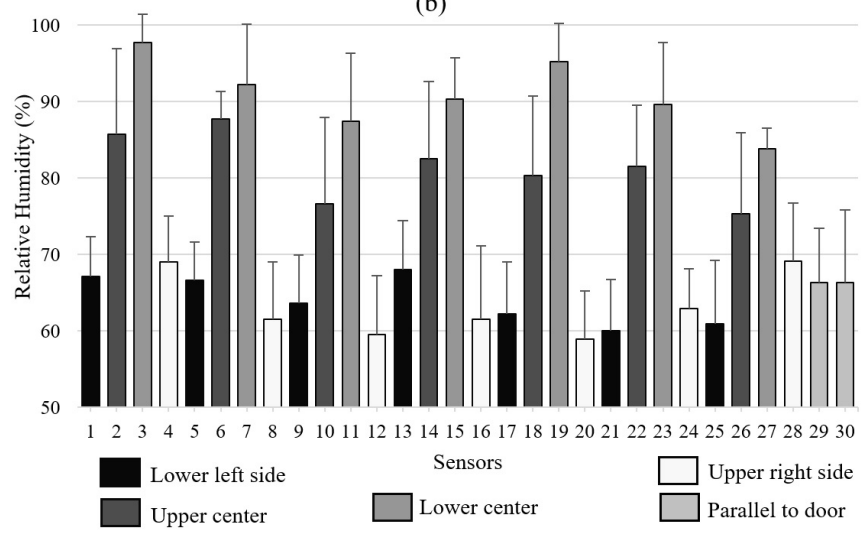

Figure 3. Mean values for air (a) temperature and (b) relative humidity measured in each sensor installed along the refrigerated vehicle extension during the monitored transport time. 
temperature and relative humidity. It was also found that, among the 14 pallets analyzed, only pallets P01, P13, P25 and P28 did not show significant differences between temperature and $\mathrm{RH}$ data collected by the sensors installed in them. Furthermore,

Table 1. Temperature and relative humidity mean values collected by sensors installed in each evaluated region within the refrigerated vehicle during transport time.

\begin{tabular}{lcc}
\hline \multirow{2}{*}{\multicolumn{1}{c}{ Position }} & \multicolumn{2}{c}{ Mean values $^{*}$} \\
\cline { 2 - 3 } & Temperature $\left({ }^{\circ} \mathrm{C}\right)$ & $\begin{array}{c}\text { Relative Humidity } \\
(\%)\end{array}$ \\
\hline Lower left side (D02) & $9.7 \pm 0.7^{\mathrm{a}}$ & $64.1 \pm 3.2^{\mathrm{c}}$ \\
Lower center (D02) & $4.2 \pm 0.6^{\mathrm{c}}$ & $90.9 \pm 4.7^{\mathrm{a}}$ \\
Upper center (E20) & $5.8 \pm 0.9^{\mathrm{b}}$ & $81.4 \pm 4.5^{\mathrm{b}}$ \\
Upper right side (E20) & $8.5 \pm 1.2^{\mathrm{a}}$ & $63.2 \pm 4.2^{\mathrm{c}}$ \\
Parallel to door (B02 e C22) & $8.8 \pm 0.1^{\mathrm{a}}$ & $66.3 \pm 0.1^{\mathrm{c}}$ \\
\hline
\end{tabular}

${ }^{*}$ Mean values followed by the same letter in the same column do not differ statistically at a significance level of $5 \%$. one can say that these pallets were homogeneous in terms of the ambient conditions in which they have been exposed to. This scenario, therefore, emphasizes the heterogeneity of the ambient conditions that table grapes were exposed to and, consequently, the heterogeneity on the shelf life that these fruits might present, based on the differences in their positioning inside the refrigerated transport vehicle.

\subsection{Grapes dynamic shelf-life loss during transportation}

Grapes mass loss through transpiration and their shelf life was estimated for each fruit box, according to their location inside the refrigerated vehicle. A cumulative algorithm as a function of the temperature and relative humidity historic conditions estimated the mass loss of the fruits during the monitoring time. The shelf life was determined by calculating the time remaining to the fruit to reach $5 \%$ of mass loss. This remaining time would be valid if the table grapes were stored in suitable conditions $\left(0{ }^{\circ} \mathrm{C}\right.$ and $95 \%$ of $\left.\mathrm{RH}\right)$ in next stages of cold chain.

Table 2. Temperatures and relative humidity data collected by individual sensors installed in different positions on a same pallet.

\begin{tabular}{|c|c|c|c|c|}
\hline \multirow{2}{*}{ Pallets } & \multicolumn{4}{|c|}{ Mean values ${ }^{*}$} \\
\hline & Temperature $\left({ }^{\circ} \mathrm{C}\right)$ & Relative Humidity (\%) & Temperature $\left({ }^{\circ} \mathrm{C}\right)$ & Relative Humidity (\%) \\
\hline \multirow[t]{2}{*}{01} & \multicolumn{2}{|c|}{ Sensor $01(\mathrm{D} 02)$} & \multicolumn{2}{|c|}{ Sensor $02(E 20)$} \\
\hline & $9.2 \pm 0.5^{\mathrm{a}}$ & $67.1 \pm 5.2^{\mathrm{a}}$ & $6.1 \pm 2.7^{\mathrm{a}}$ & $85.7 \pm 11.2^{\mathrm{a}}$ \\
\hline \multirow[t]{2}{*}{04} & \multicolumn{2}{|c|}{ Sensor 03 (D02) } & \multicolumn{2}{|c|}{ Sensor 04 (E20) } \\
\hline & $4.6 \pm 0.5^{b}$ & $97.7 \pm 3.7^{\mathrm{a}}$ & $7.4 \pm 1.5^{\mathrm{a}}$ & $69.0 \pm 6.1^{\mathrm{b}}$ \\
\hline \multirow[t]{2}{*}{05} & \multicolumn{2}{|c|}{ Sensor 05 (D02) } & \multicolumn{2}{|c|}{ Sensor 06 (E20) } \\
\hline & $9.0 \pm 0.7^{\mathrm{a}}$ & $66.6 \pm 5.0^{b}$ & $4.8 \pm 1.7^{b}$ & $87.8 \pm 3.6^{\mathrm{a}}$ \\
\hline \multirow[t]{2}{*}{08} & \multicolumn{2}{|c|}{ Sensor 07 (D02) } & \multicolumn{2}{|c|}{ Sensor 08 (E20) } \\
\hline & $3.3 \pm 0.7^{b}$ & $92.2 \pm 7.9^{\mathrm{a}}$ & $7.7 \pm 1.4^{\mathrm{a}}$ & $61.5 \pm 7.5^{b}$ \\
\hline \multirow[t]{2}{*}{09} & \multicolumn{2}{|c|}{ Sensor 09 (D02) } & \multicolumn{2}{|c|}{ Sensor 10 (E20) } \\
\hline & $10.0 \pm 0.5^{\mathrm{a}}$ & $63.6 \pm 6.3^{\mathrm{a}}$ & $5.5 \pm 2.0^{\mathrm{b}}$ & $76.6 \pm 11.3^{a}$ \\
\hline \multirow[t]{2}{*}{12} & \multicolumn{2}{|c|}{ Sensor 11 (D02) } & \multicolumn{2}{|c|}{ Sensor $12(\mathrm{E} 20)$} \\
\hline & $4.3 \pm 0.8^{\mathrm{b}}$ & $87.4 \pm 8.0^{\mathrm{a}}$ & $10.2 \pm 1.1^{\mathrm{a}}$ & $59.5 \pm 7.7^{b}$ \\
\hline \multirow[t]{2}{*}{13} & \multicolumn{2}{|c|}{ Sensor 13 (D02) } & \multicolumn{2}{|c|}{ Sensor 14 (E20) } \\
\hline & $8.9 \pm 0.8^{\mathrm{a}}$ & $68.0 \pm 6.4^{\mathrm{a}}$ & $4.9 \pm 2.4^{\mathrm{a}}$ & $82.5 \pm 10.1^{\mathrm{a}}$ \\
\hline \multirow[t]{2}{*}{16} & \multicolumn{2}{|c|}{ Sensor 15 (D02) } & \multicolumn{2}{|c|}{ Sensor 16 (E20) } \\
\hline & $4.1 \pm 0.5^{b}$ & $90.4 \pm 5.3^{\mathrm{a}}$ & $9.8 \pm 0.9^{\mathrm{a}}$ & $61.5 \pm 9.7^{b}$ \\
\hline \multirow[t]{2}{*}{17} & \multicolumn{2}{|c|}{ Sensor 17 (D02) } & \multicolumn{2}{|c|}{ Sensor 18 (E20) } \\
\hline & $10.2 \pm 1.1^{\mathrm{a}}$ & $62.2 \pm 6.8^{\mathrm{a}}$ & $5.7 \pm 1.4^{b}$ & $80.3 \pm 10.3^{a}$ \\
\hline \multirow[t]{2}{*}{20} & \multicolumn{2}{|c|}{ Sensor 19 (D02) } & \multicolumn{2}{|c|}{ Sensor 20 (E20) } \\
\hline & $3.8 \pm 0.5^{b}$ & $95.2 \pm 5.0^{\mathrm{a}}$ & $8.8 \pm 1.5^{\mathrm{a}}$ & $58.9 \pm 6.3^{b}$ \\
\hline 21 & & 02) & & $20)$ \\
\hline & $11.0 \pm 0.8^{\mathrm{a}}$ & $60.0 \pm 6.7^{b}$ & $5.8 \pm 1.8^{\mathrm{b}}$ & $81.5 \pm 8.1^{\mathrm{a}}$ \\
\hline 24 & & $02)$ & & $20)$ \\
\hline & $4.2 \pm 0.6^{b}$ & $89.6 \pm 8.1^{a}$ & $8.0 \pm 1.8^{\mathrm{a}}$ & $62.9 \pm 5.3^{b}$ \\
\hline 25 & & 02) & & $20)$ \\
\hline & $9.6 \pm 0.9^{\mathrm{a}}$ & $60.9 \pm 8.3^{a}$ & $7.6 \pm 1.2^{\mathrm{a}}$ & $75.3 \pm 10.6^{\mathrm{a}}$ \\
\hline $28^{* *}$ & & 02) & & $20)$ \\
\hline & $5.0 \pm 0.8^{\mathrm{a}}$ & $83.8 \pm 2.7^{\mathrm{a}}$ & $7.3 \pm 2.1^{\mathrm{a}}$ & $69.1 \pm 7.7^{\mathrm{a}}$ \\
\hline
\end{tabular}

${ }^{*}$ Values followed by the same letter on the same variable on the same pallet do not differ statistically at $5 \%$ of significance level; ${ }^{*}$ Comparison with the reference sensor 30 (C22) in pallet $28\left(\mathrm{~T}=8.9 \pm 2.1^{\mathrm{a}}\left({ }^{\circ} \mathrm{C}\right) ; \mathrm{RH}=66.3 \pm 9.5^{\mathrm{a}}(\%)\right)$. 
Assuming that each grape box located on each pallet had representative temperature and relative humidity means during the entire refrigerated transport, in Figure 4 are shown the estimated loss of mass for the grape boxes, considering a initial mass of the $500 \mathrm{~g}$ for each one of them. For comparison, it was calculated what the mass loss of the grapes would be if they were transported under ideal conditions of temperature and humidity $\left(0{ }^{\circ} \mathrm{C}\right.$ and $95 \%$ of $\left.\mathrm{RH}\right)$. The value found for the loss was insignificant for the evaluated transport period $(<0.01 \%$ of the initial grapes mass).

It was observed that the lower mass losses occurred for the grape boxes positioned in the lower central region of the

(a)

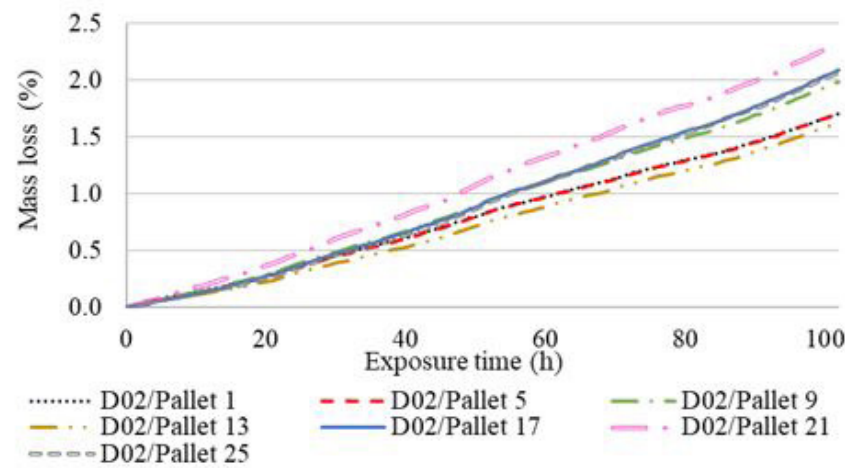

(c)

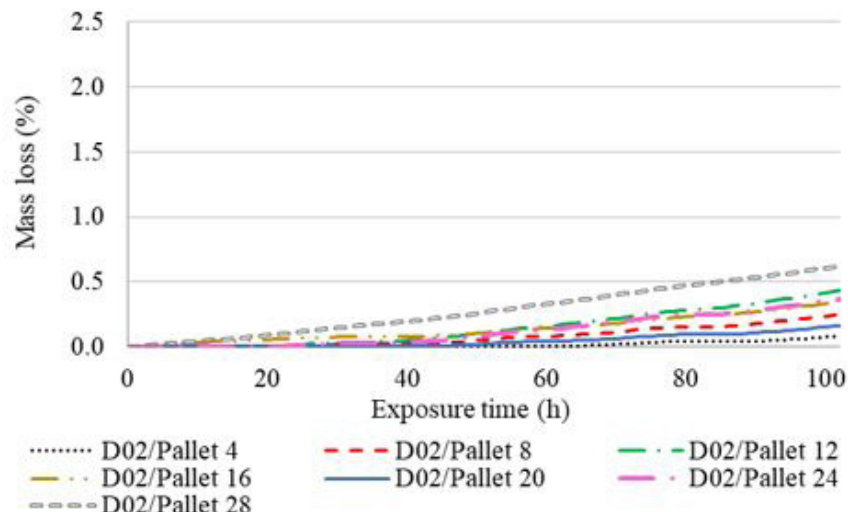

refrigerated vehicle, followed by ones located in upper center region. The higher values were observed for boxes positioned next to the door and in the upper and lower chamber sides. As expected, the lowest values were obtained in grape boxes and pallets located in the regions with the ambient conditions closest to the ideal ones. In addition, the highest water losses occurred for the fruits exposed to the conditions furthest from ideality.

The different water losses in each grape box, according to their location within the refrigerated transport vehicle, resulted in different and individualized shelf life, estimated by the instant mass loss algorithm. Figure 5 shows the shelf life of the table (b)

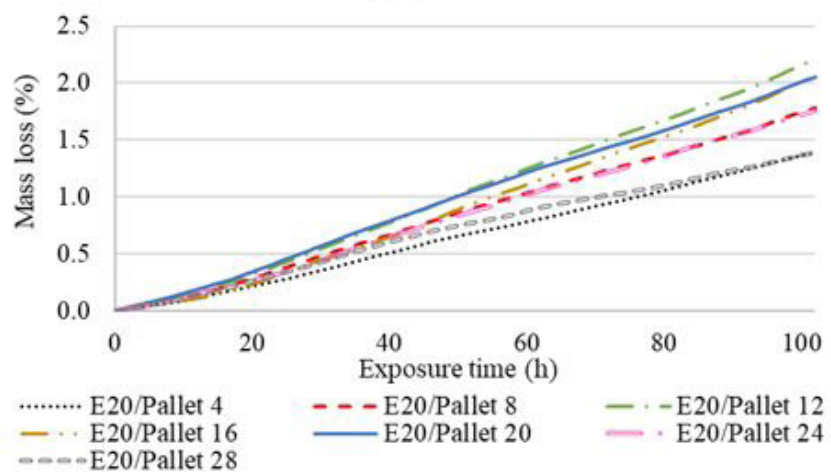

(d)

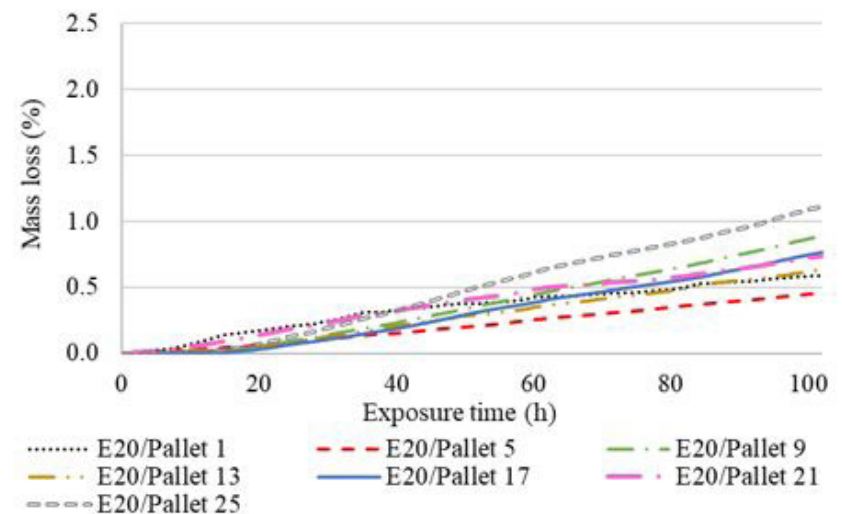

(e)

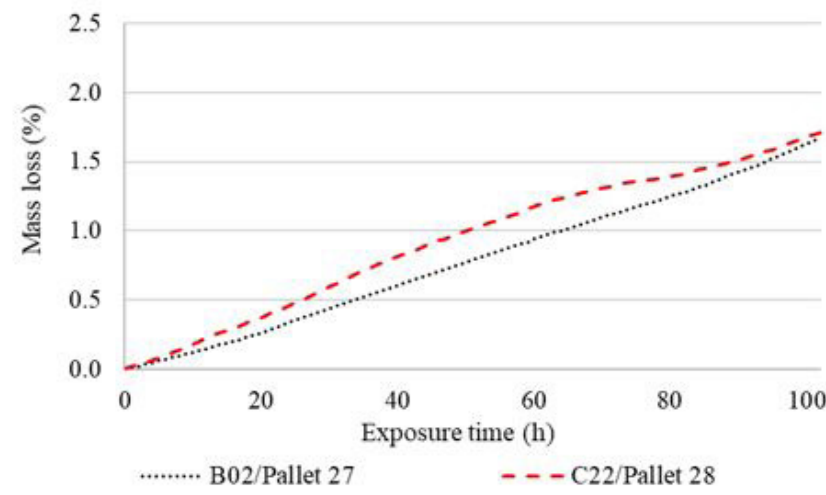

Figure 4. Mass loss (\%) of the grape bunches' boxes located in the different positions inside the refrigerated vehicle for 102 hours of transportation. (a) lower left side (D02); (b) upper right side (E20); (c) lower center (D02); (d) upper center (E20); and (e) parallel to door (B02 and C22). 
grapes monitored in each position within refrigerated vehicle after $102 \mathrm{~h}$ of transportation.

It was observed that the products with the longest shelf life, those placed in the center of the vehicle body, were exposed to the best environmental transport conditions. Under these conditions, the remaining useful life of grapes reached 156 days. If ideal conditions of transportation were used, the grapes shelf life could reach 159 days. Some authors report that grapes stored under ideal conditions might present shelf lives of up to 180 days (Chitarra \& Chitarra, 2005). On the other hand, the products with the shortest shelf life were those positioned on the sides, bottom and top of refrigerated chamber, and the ones located parallel to door.

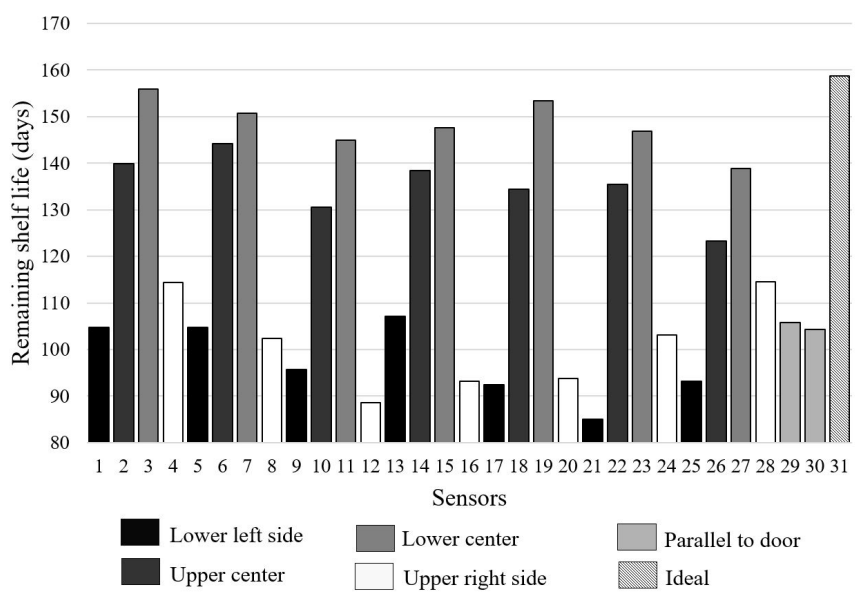

Figure 5. Shelf life of grape bunches, according to each box (sensor) positions. lower left side (D02); upper right lateral (E20); lower center (D02); upper center (E20); parallel to door (B02 and C22); and ideal storage conditions (Ideal - supposed sensor 31 ).
In this case report, the observed heterogeneity in temperature and relative humidity conditions during the $102 \mathrm{~h}$ of grapes transport, resulted in grapes with almost twice the shelf life compared to others within the same transport vehicle. Figure 6 shows a comparison between the evaluated regions of the refrigerated chamber, evaluating the differences between the mean values of shelf life, two by two, including an ideal scenario of conditioning the grapes in refrigerated transport.

The statistical analysis shows the same behavior reported for the heterogeneity of ambient conditions in the studied regions, reaffirming the combination of effects. Thus, one can observe the heterogeneity of grapes shelf life within a same refrigerated body. The sides and the near the door regions were statistically similar to each other but differed from the central ones. The lower and upper central regions were significantly different. However, they were statistically similar with the conditions considered ideal for storage $\left(0^{\circ} \mathrm{C}\right.$ and $95 \%$ of $\left.\mathrm{RH}\right)$.

Thus, one can observe the importance of not treating an entire grape load within a refrigerated vehicle as a homogeneous batch. In addition to a differentiation in the added value of the product according to its quality, reflected in the product's shelf life, the sales logistics at the distribution center must be differentiated. A more appropriated distribution logistics should consider the grape boxes of differentiated regions of the pallets that will first expire. This batch should be treated as a priority in sales logistic, respecting the time and ambient conditions in the next stage in which the products will be exposed. It should be noted that the storage of grapes in different ambient conditions to the ideal ones in the next stages of cold chain would result in shorter shelf lives than those shown in Figure 5.

Improvements in quality management in fruit and vegetable chains have already been achieved with the use of intelligent and precise technologies, such as the use of Radio

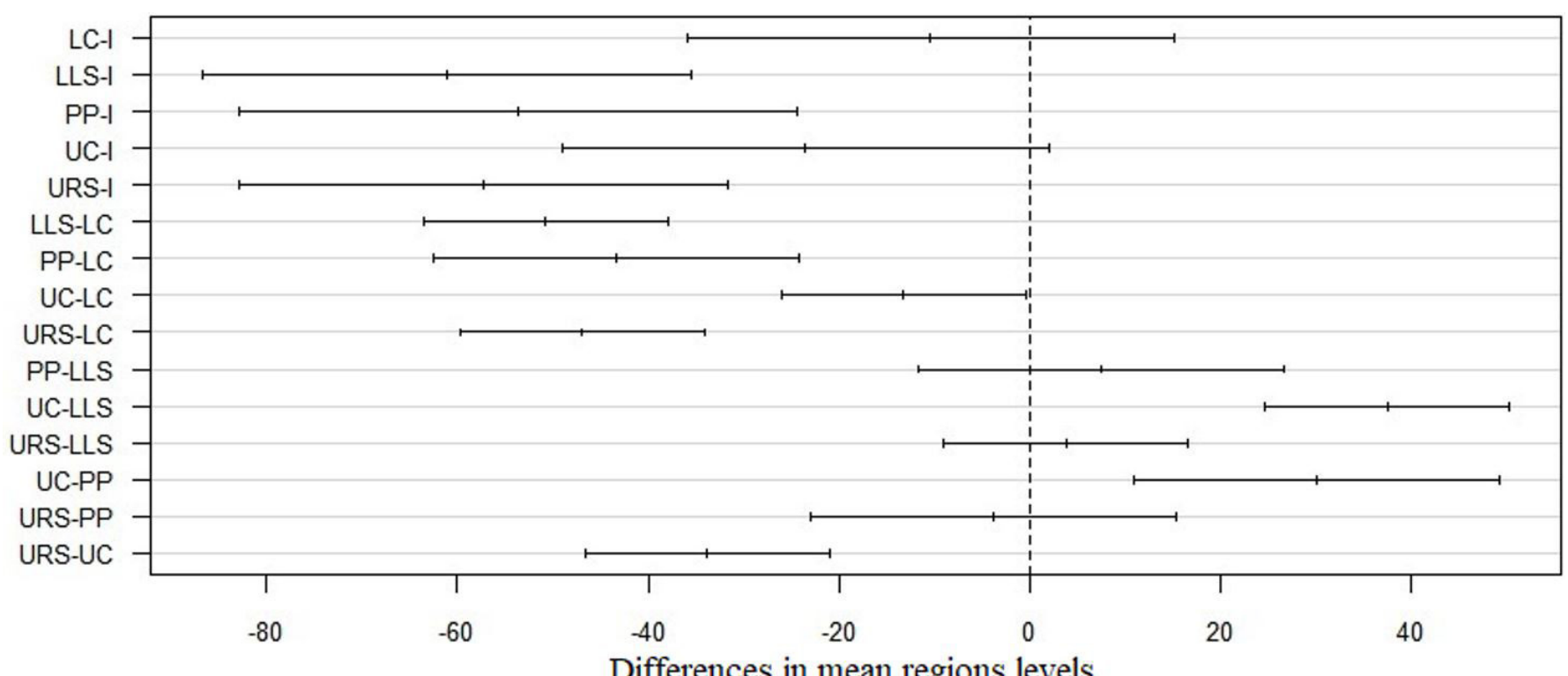

Figure 6. Comparison between the grapes shelf life for the evaluated regions. Lower left side (LLS); upper right side (URS); lower center (LC); upper center (UC); parallel to door (PP) and conditioning in ideal storage conditions (I), at 5\% of significance level. 
Frequency Identifier (RFID) and Wireless Sensor Network (RSSF) technologies for monitoring product exposure conditions (Badia-Melis et al., 2015, 2018). Associating these technologies with the application of the prediction model for dynamic shelf life of grapes, another forms of management in distribution chains of table grapes might be implemented, as using the FEFO (First Expire, First Out) methodology, instead the FIFO (First In, First Out) one (Hertog et al., 2014). This could prevent a deficient commercialization, in which all grape loading would be destined to sales sites. The FEFO methodology would be useful to provide the best form of utilization of grapes in their maximum conditions of predicted shelf lives.

In addition to monitoring ambient air conditions to assist in the assessment of the dynamic and remaining useful life of perishable products, this tool also assists in the evaluation of the process. In this case study, the refrigerated transport showed deficient air distribution, lack of relative humidity control and incorrect positioning of the temperature sensor of the refrigeration system control. These points should be improved to a better fruit conditioning. Such immediate improvements could lead to prolonging the life of table grapes and reducing losses.

\section{Conclusions}

There were significant variations in temperature and relative humidity inside the refrigerated vehicle body during table grapes transportation stage. It was also possible to conclude the heterogeneity of ambient conditions within a same stacked grape pallet. It was concluded that grapes shelf life varied according to the position of each box stacked on the pallets, and to the pallets position within refrigerated transport vehicle. The proof of the heterogeneity of the remaining useful life of the grape encourages the replacement of the FIFO (First in, First out) methodology, widely used in Brazil, by the FEFO (First expired, First out) one. It takes into account the dynamic shelf life of perishable products, which is a function of the fruit's metabolism and the mass loss occurring due to ambient conditions and the time in which they are exposed to that environment.

The monitoring of different points within the refrigerated chamber was a better tool to characterize the representative temperature of the transported batch. The single point monitoring, usual in refrigerated transport stages, may not represent the worst situation for fruits conditioning, which would result in an overestimation of the product's shelf life.

\section{Acknowledgements}

The authors would like to thank FAPESP for the research funding, the BT9 company for providing the Xsense technology, and "Espaço da Escrita - Pró-Reitoria de Pesquisa - UNICAMP" - for the language services provided.

\section{References}

Antoine, C. (1888). Tensions des vapeurs; nouvelle relation entre les tensions et les températures. Comptes Rendus de l'Académie des Sciences, 107, 681-684, 778-780, 836-837.
Artés-Hernández, F., Tomás-Barberán, F. A., \& Artés, F. (2006). Modified atmosphere packaging preserves quality of SO2-free "Superior seedless" table grapes. Postharvest Biology and Technology, 39(2), 146-154. http://dx.doi.org/10.1016/j.postharvbio.2005.10.006.

Aung, M. M., \& Chang, Y. S. (2014). Temperature management for the quality assurance of a perishable food supply chain. Food Control, 40, 198-207. http://dx.doi.org/10.1016/j.foodcont.2013.11.016.

Badia-Melis, R., McCarthy, U., Ruiz-Garcia, L., Garcia-Hierro, J., \& Robla Villalba, J. I. (2018). New trends in cold chain monitoring applications: a review. Food Control, 86, 170-182. http://dx.doi.org/10.1016/j. foodcont.2017.11.022.

Badia-Melis, R., Ruiz-Garcia, L., Garcia-Hierro, J., \& Villalba, J. I. R. (2015). Refrigerated fruit storage monitoring combining two different wireless sensing technologies: RFID and WSN. Sensors, 15(3), 4781-4795. http://dx.doi.org/10.3390/s150304781. PMid:25730482.

Becher, B. R., Misra, A., \& Fricke, B. A. (1995). Bulk refrigeration of fruits and vegetables, part I: theoretical considerations of heat and mass transfer. Kansas City: University of Missouri-Kansas City.

Cantwell, M. (2015). Water loss and postharvest quality. In Postharvest Technology of Horticultural Crops Short Course. Berkeley: University of California.

Chitarra, M. I. F., \& Chitarra, A. B. (2005). Pós-colheita de frutas e hortaliças: fisiologia e manuseio (2. ed.). Lavras: Universidade Federal de Lavras.

Crisosto, C. H., Smilanick, J. L., \& Dokoozlian, N. K. (2001). Table grapes suffer water loss, stem browning during cooling delays. California Agriculture, 55(1), 39-42. http://dx.doi.org/10.3733/ca.v055n01p39.

Derens-Bertheau, E., Osswald, V., Laguerre, O., \& Alvarez, G. (2015). Cold chain of chilled food in France. International Journal of Refrigeration, 52, 161-167. http://dx.doi.org/10.1016/j.ijrefrig.2014.06.012.

Hertog, M. L. A. T. M., Uysal, I., McCarthy, U., Verlinden, B. M., \& Nicolai, B. M. (2014). Shelf life modelling for first-expiredfirst-out warehouse management. Philosophical Transactions of the Royal Society A: Mathematical, Physical and Engineering Sciences, 372(2017), 20130306. http://dx.doi.org/10.1098/rsta.2013.0306.

Jedermann, R., Becker, M., Gorg, C., \& Lang, W. (2011). Testing network protocols and signal attenuation in packed food transports. International Journal of Sensor Networks, 9(3/4), 170-181. http:// dx.doi.org/10.1504/IJSNET.2011.040238.

Jedermann, R., Ruiz-Garcia, L., \& Lang, W. (2009). Spatial temperature profiling by semi-passive RFID loggers for perishable food transportation. Computers and Electronics in Agriculture, 65(2), 145-154. http://dx.doi.org/10.1016/j.compag.2008.08.006.

Kader, A. A. (2002). Postharvest biology and technology: an overview. In A. A. Kader (Ed.), Postharvest technology of horticultural crops (Vol. 3). Oakland: University of California. http://doi.org/10.1016/j. postharvbio.2008.03.007.

Leonardi, C., Baille, A., \& Guichard, S. (1999). Effects of Fruit Characteristics and Climatic Conditions on Tomato Transpiration in a Greenhouse. Horticultural Science and Biotechnology, 74(6), 748-756. http://dx.doi.org/10.1080/14620316.1999.11511183.

Lopresti, J., Villalta, O., \& Tomkins, B. (2016). Predicting rachis browning and quality loss in Vitis Vinifera L 'Thompson Seedless' during cool storage. Retrieved from http://tablegrape.geometryit.com/wp-content/ uploads/2016/02/1300-John-Lopresti-Predicting-rachis-browningand-quality-loss-during-cold-storage.pdf

Pereira, E., Silva, R. G. B., Spagnol, W. A., \& Silveira, V. Jr. (2017). Water loss in table grapes: model development and validation under 
dynamic storage conditions. Food Science and Technology, 38(3), 473-479. http://dx.doi.org/10.1590/1678-457x.08817.

Ruiz-Garcia, L., \& Lunadei, L. (2010). Monitoring cold chain logistics by means of RFID. In C. Turcu (Ed.), Sustainable radio frequency identification solutions (pp. 37-50). London: IntechOpen. http:// dx.doi.org/10.5772/8006.

Ruiz-Garcia, L., Barreiro, P., \& Robla, J. I. (2008). Performance of ZigBee-Based wireless sensor nodes for real-time monitoring of fruit logistics. Journal of Food Engineering, 87(3), 405-415. http:// dx.doi.org/10.1016/j.jfoodeng.2007.12.033.

Ruiz-Garcia, L., Barreiro, P., Robla, J. I., \& Lunadei, L. (2010a). Testing zigBee motes for monitoring refrigerated vegetable transportation under real conditions. Sensors, 10(5), 4968-4982. http://dx.doi. org/10.3390/s100504968. PMid:22399917.

Ruiz-Garcia, L., Steinberger, G., \& Rothmund, M. (2010b). A model and prototype implementation for tracking and tracing agricultural batch products along the food chain. Food Control, 21(2), 112-121. http://dx.doi.org/10.1016/j.foodcont.2008.12.003.
Sargent, S. A., Ritenour, M. A., Brecht, J. K., \& Bartz, J. A. (2007). Handling, cooling, sanitation, techniques for maintaining postharvest quality. In University of Florida (Ed.), Vegetable production handbook (pp. 97-109). Florida: Horticultural Sciences Department. Retrieved from https://hos.ifas.ufl.edu/media/hosifasufledu/documents/ Handling,-Cooling-and-Sanitation-Techniques-for-MaintainingPostharvest-Quality.pdf

Sastry, S. K., \& Buffington, D. E. (1983). Transpiration rates of stored perishable commodities: a mathematical model and experiments on tomatoes. International Journal of Refrigeration, 6(2), 84-96. http:// dx.doi.org/10.1016/0140-7007(83)90050-6.

Sastry, S. K., Baird, C. D., \& Buffington, D. E. (1978). Transpiration rates of certain fruits and vegetables. ASHRAE Transactions, 84(1), 237-254.

Sonker, N., Pandey, A. K., \& Singh, P. (2016). Strategies to control postharvest diseases of table grape: a review. Journal of Wine Research, 27(2), 105-122. http://dx.doi.org/10.1080/09571264.2016.1151407.

Thompson, J. F. (2002). Transportation. Postharvest Technology of Horticultural Crops, 3311, 259-269. 